\title{
O Programa Institucional de Bolsas de Iniciação à Docência como proposta para a reflexão das Ciências Biológicas na Educação Básica, Graduação e Pós- Graduação
}

\section{RESUMO}

Cassia Monica Sakuragui cmsakura12@gmail.com Universidade Federal do Rio de Janeiro, Rio de Janeiro, Brasil.

\section{Alexandre Pedro Selvatti Ferreira} Nunes

$\underline{\text { apselvatti@gmail.com }}$

Universidade Federal do Rio de Janeiro, Rio de Janeiro, Brasil.

Dilton Ribeiro do Couto Junior

junnior 2003@yahoo.com.br

0000-0002-5221-7135

Universidade do Estado do Rio de

Janeiro, Rio de Janeiro, Brasil.
O objetivo deste trabalho é discutir os conteúdos abordados no primeiro ano do Ensino Médio e temas transversais, no contexto da estrutura curricular do Curso de Licenciatura em Ciências Biológicas da Universidade Federal do Rio de Janeiro (UFRJ), e como o Programa Institucional de Bolsa de Iniciação à Docência (Pibid) se constitui numa proposta relevante para suscitar conjecturas sobre esta estrutura. Além disso, o texto visa refletir sobre as contribuições da Pós-Graduação neste processo, por meio da atuação dos alunos que desenvolvem estágio de docência nos componentes curriculares do curso.

PALAVRAS-CHAVE: Ensino Médio. Graduação. Pós-Graduação. Pibid. Biologia. 


\section{INTRODUÇÃO}

O Programa Institucional de Bolsas de Iniciação à Docência (Pibid) foi criado com a finalidade de valorizar as práticas pedagógicas do magistério e de subsidiar teórica e metodologicamente os estudantes de licenciatura. O programa apresenta como objetivo ampliar as ações acadêmicas voltadas à formação inicial de professores nos cursos de licenciatura das instituições de educação superior, além de proporcionar aos futuros professores a participação em experiências metodológicas, tecnológicas e práticas inovadoras e interdisciplinares nas escolas. Dentro desta perspectiva, o Pibid busca uma postura em sala de aula que supere a visão de que os conhecimentos sejam trabalhados, com os estudantes, única e exclusivamente a partir de manuais didáticos com o objetivo de sistematizar conteúdos requeridos para a mera aprovação na instituição. A intenção não é a de criar aplicabilidades técnicas na prática docente porque, assim como Sonia Kramer (2007, p. 152) declara, nos "preocupa também que [os livros didáticos] sejam usados como receitas ou modelos, parecendo querer anular os processos que os professores vivem, parecendo querer apagar suas experiências!". Caminhando numa ótica semelhante, Carvalho (1997) argumenta que repensar a prática pedagógica é imprescindível para que haja uma mudança significativa nos processos educacionais.

Se por um lado há inúmeras críticas sobre a massificação do ensino a partir do uso dos manuais pedagógicos, por outro lado Nóvoa (1999) critica o fato de que "os professores não podem refugiar-se numa atitude 'defensiva' e têm que estar preparados para enfrentar as interpelações dos seus alunos" (p. 19). Na medida em que as pesquisas no campo científico são desenvolvidas e novas descobertas são feitas dentro das diferentes áreas do saber, cabe questionar: quais os critérios para selecionar as descobertas que serão discutidas com os estudantes da licenciatura? Como esses conhecimentos chegam até a escola? Quais as contribuições dos cursos de licenciatura na promoção de reflexões sobre os processos de ensinar e aprender?

Orientado por essas perguntas, o projeto Pibid desenvolvido no curso de Biologia da Universidade Federal do Rio de Janeiro (UFRJ) também busca convidar os alunos a refletir sobre outros temas que consideramos igualmente importantes, e que foram formulados por Jacobucci $(2011$, p. 180):

\footnotetext{
a formação inicial dos futuros professores no campo da divulgação científica, das intencionalidades discretas do currículo em vigência e a complexidade do exercício profissional, do discurso dos professores universitários e os ecos sobre os licenciandos, da concepção de vir a ser professor e da importância da comunicação da Ciência na contemporaneidade.
}

Ainda que nossa tarefa aqui não seja buscar responder de forma definitiva as perguntas tecidas ao longo do texto, nos parece importante um olhar crítico diante dos desafios apresentados pelos processos educacionais nos cursos de licenciatura. Para isso, buscamos auxílio em autores do campo da educação para, no presente texto, discutirmos o Pibid no contexto da estrutura curricular do Curso de Licenciatura em Ciências Biológicas da UFRJ.

$\mathrm{O}$ texto foi organizado em quatro partes. Na primeira, debatemos o projeto 
desenvolvidas nelas. Na segunda parte do texto, situamos o projeto Pibid no contexto da Lei de Diretrizes e Bases da Educação Nacional (LDB) e dos Parâmetros Curriculares Nacionais (PCN's). Em seguida, na terceira seção, apontamos as contribuições da Pós-Graduação no projeto Pibid a partir do Plano Nacional de PósGraduação (PNPG). Por fim, concluímos sobre a importância de se estabelecer maiores vínculos entre a Pós-Graduação, a Graduação e o Ensino Médio, compreendendo a relevância do Pibid-UFRJ na promoção de novos processos de ensino-aprendizagem nas escolas.

\section{Pibid, campo de trabalho e procedimentos metodológicos}

O Pibid-Biologia da UFRJ tem como proposta a realização de atividades com alunos do Ensino Médio, desenvolvidas pelos professores supervisores, licenciandos e coordenadores. Essas visam o enriquecimento e ampliação do conjunto de exercícios realizados em sala de aula.

O campo de trabalho do projeto Pibid-Biologia-UFRJ 2009-2012 incluiu quatro escolas da rede pública de ensino do Rio de Janeiro, a saber:

a) CIEP Professor César Pernetta, localizado no bairro de Bonsucesso, em uma das maiores comunidades de baixa renda do Rio de Janeiro, o Complexo da Maré, com funcionamento do Ensino Médio nos três turnos. A instituição apresenta cerca de 900 alunos, sendo 340 alunos ingressantes por ano;

b) Colégio Estadual Antônio Prado Junior, localizado no bairro da Tijuca, o qual recebe alunos das escolas da rede municipal e também da região do Grande Rio, com funcionamento do Ensino Médio nos três turnos. Há 2000 alunos na escola, sendo 650 o número de ingressantes por ano;

c) Colégio Estadual Olinto Gama Botelho, localizado no bairro de Pilares, apresenta o funcionamento do Ensino Médio nos três turnos. O colégio tem 520 alunos, sendo 220 o número de ingressantes por ano;

d) Colégio Estadual Sargento Wolff, localizado em Duque de Caxias, também está situada numa das maiores comunidades de baixa renda do Rio de Janeiro, próximo ao lixão de Gramacho, com funcionamento do Ensino Médio em dois turnos. $O$ colégio tem cerca de 1000 alunos, com 300 ingressantes por ano.

Os procedimentos metodológicos englobaram a formação dos grupos de trabalho onde os licenciandos foram divididos em quatro grupos de três integrantes, de acordo com a proximidade geográfica das respectivas residências ou por afinidade. Foi realizado um diagnóstico inicial das escolas com visitação e contatos, com posterior organização e planejamento de atividades por escola, seguindo principalmente os conteúdos abordados pelo professor supervisor em sala de aula, com ênfase nos conteúdos "sensíveis", ou seja, aqueles considerados de difícil pelos alunos. As ações dialogadas nas escolas foram basicamente no contra-turno dos alunos e um processo de avaliação contínuo foi mantido ao longo do processo, através do relato oral e relatórios escritos apresentados periodicamente. As quatro equipes do Pibid-Biologia se reuniram semanalmente com a coordenadora para discutir: 1 . Apresentação das atividades semanais nas seminários; 4. Diálogos sobre a semana. As reuniões nas escolas foram realizadas 
semanalmente e permitiram a organização de atividades e projetos com as supervisoras. Periodicamente foram realizadas reuniões entre a coordenadora, a supervisora e os licenciandos em cada uma das escolas. Todos os bolsistas tinham horários e compromissos bem definidos nas escolas em que atuavam, sob constante orientação tanto das professoras supervisoras quanto da coordenadora. No âmbito das escolas, basicamente os bolsistas participaram de atividades no contra turno das turmas do professor supervisor, mas eventualmente acompanharam as atividades nas salas de aula e organizaram aulas práticas nos laboratórios de ciências.

Nas quatro escolas, foram orientados trabalhos e projetos extraclasses, de modo a incentivar o trabalho dos alunos com conteúdos de biologia, principalmente aqueles diretamente ligados ao dia-a-dia dos mesmos tanto na escola, como na comunidade. O enfoque, nesse caso, foi mais ecológico e voltado para o entendimento do homem e suas relações com o meio ambiente. Nas quatro escolas, foram realizadas feiras de ciências com forte apoio da equipe do projeto. O projeto possibilitou a produção de jogos didáticos, apostilas de estudos, protocolos de aulas práticas, visitas guiadas, além de atividades de apoio. Como exemplos de jogos criados para atender às demandas do projeto, mencionamos: 1. Jogo "Origem da Vida", que consiste em cartas com descrição de experimentos, fotos com nomes de cientistas e descrição de teorias. $O$ aluno recebia uma carta e relacionava o cientista ao seu experimento e à sua teoria; 2 . Dinâmica "Responda Criativo", em que os alunos utilizavam giz de cera, cartolina e lápis de cor para responder com suas próprias palavras ou desenhos perguntas sobre a origem da vida; 3. Brincadeira "Boliche ecológico", onde seis pinos diferentes, feitos com garrafa pet, representando peixe, algas, invertebrados marinhos, lixo, pesca excessiva em épocas reprodutivas e vazamento de petróleo foram dispostos lado a lado voltados para o jogador, alternando um organismo marinho com um "agente poluidor" ou atitude incorreta. $\mathrm{O}$ jogador utilizava um coco verde (fruta) como bola de boliche, sendo estimulado a preservar o meio ambiente, não abatendo os animais e algas.

Os licenciandos participantes do projeto Pibid-UFRJ estiveram, portanto, comprometidos e engajados na tarefa de conhecer as relações de ensinoaprendizagem nos cotidianos escolares do Ensino Médio. $O$ trabalho do projeto é realizado dentro de uma perspectiva dialógica e participativa, conforme Alves (2008, p. 20, grifo da autora) defende: "percebo que só é possível analisar e começar a entender o cotidiano escolar em suas lógicas, através de um grande mergulho na realidade cotidiana da escola e nunca exercitando o tal olhar distante e neutro que me ensinaram e aprendi a usar".

De maneira geral observou-se uma melhora sensível e crescente no desempenho dos alunos que se envolveram com o projeto Pibid, como por exemplo, no aumento da atenção às atividades na sala de aula e no rendimento dos alunos. A leitura e compreensão de textos também sofreram melhora, entretanto, chamou atenção um aumento no interesse pelos temas das ciências e transversos nestes alunos e, consequentemente, na cultura geral dos mesmos. Numa análise dos resultados, ressaltamos a efetividade das ações no contexto dos conteúdos formais da disciplina de Biologia, mas ao mesmo tempo chamamos a atenção para uma das razões para o insucesso neste nível dos estudos: a relativa falta de interesse dos alunos pelas práticas de leitura e escrita trabalhadas na escola prejudicando a compreensão de textos, científicos ou não. 
Sobre isso, Oswald e Rocha (2013), num estudo desenvolvido com jovens do Ensino Médio de escolas públicas e particulares do Estado do Rio de Janeiro, verificaram que a experiência contemporânea de leitura dos estudantes se contrapõe com o discurso escolar, que ainda os identifica como não leitores. De acordo com os autores, a escola, "na maioria das vezes, valoriza preferencialmente a leitura canônica, desenvolvida individualmente, que, supostamente, aperfeiçoaria a linguagem e promoveria a consciência crítica do leitor" (p. 281). Caberia questionar como o Pibid-UFRJ promoveria maiores pontes entre a escola e a universidade a partir de experiências de leitura e escrita. Sobre o que leem e escrevem os jovens do Ensino Médio? E qual a relação dos professores que atuam no magistério com as práticas de leitura e escrita? Kramer (2007, p. 59) também levanta inúmeras críticas e questiona o uso dos livros didáticos na sala de aula: "E os livros? Apenas guardam conhecimentos retalhados e mumificados em informações que é preciso acumular? Tornados mercadorias, os livros didáticos não apagam simplesmente a condição de produtores de seus autores?". Cabe refletir também sobre o lugar ocupado pelos alunos nas escolas do Ensino Médio, quando há uma ênfase não pela experiência prazerosa proporcionada pela prática da leitura e da escrita, mas na assimilação de uma grande quantidade de informação. Assim, é dentro dessa perspectiva que a proposta do Pibid se orienta, visando desconstruir a impressão negativa dos alunos sobre as práticas de leitura e escrita.

Kramer (2007) formula a seguinte pergunta, imprescindível para que seja refletida a relação teoria e prática no cotidiano do trabalho docente: as "estratégias de formação em serviço têm favorecido que os professores relatem suas experiências e produzam conhecimentos, ou eles tão-somente são reduzidos à condição de audiência passiva de informações 'acadêmicas' desvinculadas de seu saber e de sua prática?" (p. 54, grifo da autora). Diante das palavras da autora e da relação dos alunos com as práticas de leitura e escrita, outras perguntas podem ser lançadas: como promover metodologias de ensino-aprendizagem no campo das ciências biológicas, que estejam em sintonia com a realidade sociocultural dos estudantes do Ensino Médio? Quais os critérios para selecionar os conhecimentos que os alunos deverão aprender? Qual o papel das instituições de ensino superior na formação dos futuros professores do Ensino Médio? Para Nóvoa (1999, p. 20),

A "refundação da escola" tem muitos caminhos, mas todos eles passam pelos professores. profissão representou, no passado, um dos lugares onde a idéia de escola foi inventada. No presente, o seu papel é essencial para que a escola seja recriada como espaço de formação individual e de cidadania democrática.

O projeto Pibid-Biologia-UFRJ visa apresentar aos alunos diferentes fontes de informação e diferentes formas de discuti-la. Para tanto, no início do projeto foi selecionada uma bibliografia básica, cuja interface entre biologia, matemática e química promovesse o interesse dos alunos, seja pela inserção em características literárias ficcionais, quanto pelos vínculos mais estreitos entre a realidade dos alunos e essas diferentes áreas do conhecimento. Como vemos no seguinte exemplo das "Ciência dos Super-heróis": era mesmo uma aranha que tecia teia, a escolhida pelo autor do Homem-Aranha? Havia suficiente coeficiente elástico nessa teia, a ponto de paralisar grandes corpos em movimento? E quais outras relações seriam tecidas entre os conhecimentos científicos e os super-heróis? Como os processos de ensino-aprendizagem, na escola, se beneficiariam ao 
conhecer os interesses de seus estudantes? Conforme nos alerta Kramer (2007), é preciso o cuidado com os chamados textos "pedagógicos": "Produzidos para os professores, sem entoação, gesto, herói ou contextos múltiplos - como se não houvesse um leitor ativo -, tais textos mais parecem receituários ou discursos normativos... Palavras nuas, abstratas" (KRAMER, 2007, p. 85).

Eis o desafio que consideramos importante quando pretendemos descentralizar a figura do professor, reconhecido, muitas vezes, como aquele que supostamente detém todo o conhecimento e que, consequentemente, deveria transmitir o que sabe àqueles que pouco ou nada sabem: "aprender a substituir a manipulação pela comunicação, o controle do outro pela interação com o outro, e a transferência de informações entre sujeitos desiguais pela troca de conhecimentos entre pessoas diferentes" (BRANDÃO, 2003, p. 60, grifos do autor). Ainda que o autor esteja se referindo ao ofício da pesquisa, defendemos também uma perspectiva dialógica no trabalho em sala de aula. Como construir no projeto Pibid-UFRJ estratégias metodológicas que criem o desejo dos alunos do Ensino Médio pelo aprendizado dos conhecimentos das ciências biológicas?

Brandão (2003, p. 69) mostra que determinado tema é investigado e pesquisado "quando descobrimos [o] que não sabemos ainda, ou que não sabemos o bastante para ensinar" e, por isso, torna-se de suma importância que os estudantes dos cursos de licenciatura também desempenhem o ofício da pesquisa para aprimorar a formação e contribuir com a produção de conhecimento. 0 próprio fazer pedagógico exige reflexão diária do professor, pois no processo educacional não existem manuais e respostas prontas. Diante do exposto, concordamos que, nos processos de ensinar e aprender, o "por quê" se apresenta como uma alternativa mais interessante do que o "pois é". Segundo mostra Marinho (2006, p. 20):

Penso - e sempre digo isso a meus alunos e alunas - que, para melhorar a escola e a educação, devemos fazer uma pedagogia da incerteza. É o que chamo de pedagogia do 'por quê?', ao contrário da pedagogia do 'pois é', da educação das certezas e dos saberes pré-fixados.

Dentro desse contexto, cabe questionarmos a forma como determinadas práticas educacionais vão ao encontro de uma perspectiva que prima pela mera valorização da "transmissão de conhecimento" na sala de aula. Na contramão desse pensamento, defendemos com este trabalho a necessidade de reiterar as palavras de Paulo Freire (1987), para quem "Ninguém educa ninguém, ninguém educa a si mesmo, os homens se educam entre si" (p. 68). Dessa forma, concordamos com a crítica de Freire sobre a "educação bancária", exercida através da figura de um sujeito (o professor) que supostamente saberia mais e, portanto, "depositaria" conhecimentos naquele sujeito (o estudante) que supostamente saberia menos. Ao reconhecer que "o conhecimento se produz coletivamente com o outro, o professor rompe com uma abordagem em que as vozes dos sujeitos permaneçam invisíveis, silenciadas e sem a presença do caráter dialógico na relação" (COUTO JUNIOR, NUNES e VELLOSO, 2014, p. 41). Em função disso, o projeto Pibid reitera a importância do papel dialógico nos processos educacionais, reconhecendo que os termos "ensino" e "aprendizagem" são indissociáveis porque tanto os ensinamentos quanto as aprendizagens se retroalimentam.

Ao colocarmos em funcionamento um fazer pedagógico dialógico, rompemos com uma imagem muito comum do espaço escolar, muitas vezes identificado 
como o "lugar onde o adulto [o professor] só faz perguntas quando já sabe as respostas" (KRAMER, 2007, p. 145). Brandão (2003, p. 167) sugere que a transformação de "uma turma passiva de alunos em uma comunidade ativa de criação de aprendizados" emerge quando o ensino deixa de ser o foco e a aprendizagem torna-se o centro: da palavra que é pronunciada com a certeza do professor à palavra que, coletivamente, adquire significado pelos envolvidos no processo de ensino-aprendizagem. Ou ainda, segundo coloca o autor, "de um ensino centrado no dizer a palavra sabida para uma aprendizagem fundada no buscarmos juntos a palavra que nos diga algo" (BRANDÃO, 2003, p. 167 grifos do autor).

A utilização de práticas de campo, práticas laboratoriais, jogos, vídeos, debates, visitas a museus e mostras, dentre outras estratégias pedagógicas, visam estimular a construção conceitual para que os alunos elaborem espontaneamente as relações entre os diferentes tópicos das ciências biológicas. Pensar ludicamente a mediação dos conhecimentos da biologia no Ensino Médio seria uma estratégia para criar nos estudantes e professores, o desejo e a necessidade de buscar novas experiências de ensino-aprendizagem. Para Leite (2007), o lúdico muitas vezes encontra-se ausente da instituição escolar, e reforça a importância do lúdico na formação tanto dos alunos quanto de seus professores.

Atividades como jogos de mesa e os jogos cooperativos também constituemse como outras possibilidades para serem incorporadas na escola, considerando a ludicidade como aspecto fundamental no trabalho com os estudantes do Ensino Médio. Em uma pesquisa que enfoca a busca por estratégias de ensino, Oliveira (2005) também propôs a construção de maquetes e a utilização de sucatas e material reciclável, os quais facilitaram a compreensão de certos conceitos e conteúdos da disciplina de Histologia em um curso de Biologia do Ensino Superior. Dessa forma, a autora defende que o professor trabalhe de forma interdisciplinar a partir de metodologias de ensino que estejam em sintonia da realidade do aluno.

As escolas de educação básica participantes do projeto Pibid puderam ampliar - leque de suas práticas pedagógicas e se viram diante de inúmeras inovações metodológicas que tinham como principal objetivo atender às suas demandas educacionais específicas. Somado a isso, a universidade teve a oportunidade para se aproximar dos cotidianos escolares de estudantes da rede pública de ensino do Rio de Janeiro ao estreitar os vínculos sociais, afetivos e acadêmicos com diversas instituições da educação básica.

\section{A Lei de Diretrizes e Bases da Educação Nacional (LDB) e as abordagens do Pibid}

De acordo com Faria Júnior e Faria (1999), conteúdo seria definido como o conjunto de conhecimentos sistemáticos sobre o fenômeno educativo. O conteúdo de um determinado componente curricular é aquilo que, da ciência, foi pedagogizado e, consequentemente, é trabalhado nas práticas educacionais em seus diversos níveis de ensino. Para não se tornarem a própria razão do ensino, o conteúdo é mais que o simples resultado de uma seleção de diversas áreas temáticas, e sua abordagem, numa perspectiva mais ampla, deve estar orientada para a natureza conceitual, procedimental e atitudinal. 
significativa (PCN's, 1998). Os temas transversais às Ciências Biológicas (ética, saúde, meio ambiente, pluralidade cultural, e orientação sexual) abordados nos PCN's devem atender às necessidades de cada região ou escola e serem desenvolvidos dentro de uma perspectiva interdisciplinar. Dessa forma, devem ser observadas as características e potenciais cognitivos, motores, afetivo-sociais, interesses e necessidades, faixa etária, bem como as competências e habilidades dos educandos. A atualização dos conteúdos e a possibilidade de integração com outros temas e disciplinas são necessárias para que o aluno tenha acesso às descobertas científicas e apresente uma melhor compreensão sobre a intersecção das diversas áreas do conhecimento.

O Art. 26 da Lei de Diretrizes e Bases da Educação Nacional (LDB) determina a obrigatoriedade, nessa Base Nacional Comum, de

estudos da Língua Portuguesa e da Matemática, o conhecimento do mundo físico e natural e da realidade social e política, especialmente do Brasil, o ensino da arte [...] de forma a promover o desenvolvimento cultural dos alunos, e a Educação Física, integrada à proposta pedagógica da escola.

Já o Art. 36 da LDB estabelece, em seu parágrafo 1ํㅡ, as competências que o aluno, ao final do Ensino Médio, deve demonstrar: "Os conteúdos, as metodologias e as formas de avaliação serão organizados de tal forma que ao final do ensino médio o educando demonstre: I - domínio dos princípios científicos e tecnológicos que presidem a produção moderna...". Além disso, o perfil de saída do aluno do Ensino Médio está diretamente relacionado às finalidades desse ensino, conforme determina o Art. 35 da Lei:

\begin{abstract}
O Ensino Médio, etapa final da Educação Básica, com duração mínima de três anos, terá como finalidade : I - a consolidação e aprofundamento dos conhecimentos adquiridos no ensino fundamental, possibilitando o prosseguimento de estudos; II - a preparação básica para o trabalho e a cidadania do educando como pessoa humana, incluindo a formação ética e o desenvolvimento da autonomia intelectual e do pensamento crítico; III - a compreensão dos fundamentos científico-tecnológicos dos processos produtivos, relacionando a teoria com a prática, no ensino de cada disciplina.
\end{abstract}

A reforma curricular do Ensino Médio estabelece a divisão do conhecimento escolar em três áreas, a saber: a) Linguagens, Códigos e suas Tecnologias, b) Ciências da Natureza, Matemática e suas Tecnologias e c) Ciências Humanas e suas Tecnologias. Essa divisão tem como base a reunião dos conhecimentos que compartilham objetos de estudo e, portanto, mais facilmente se comunicam, criando condições para que a prática escolar se desenvolva numa perspectiva interdisciplinar. $\mathrm{O}$ fato de estes Parâmetros Curriculares terem sido organizados em cada uma das áreas por disciplinas potenciais não significa que essas são obrigatórias ou mesmo recomendadas. O que é obrigatório pela LDB ou pela Resolução no 03/98 são os conhecimentos que estas disciplinas recortam e as competências e habilidades a elas referidas e mencionadas nos documentos. Nas Ciências da Natureza, Matemática e suas Tecnologias, onde a Biologia se insere, de 
acordo com o documento, o desenvolvimento de conteúdos e atividades na área visa a compreensão das ciências como construções humanas. Isso permite entender e explorar como elas se desenvolvem por acumulação, continuidade ou ruptura de paradigmas, relacionando o desenvolvimento científico com a transformação da sociedade, o entendimento e aplicação de métodos e procedimentos próprios das Ciências Naturais.

Cabe ressaltar que nas escolas que participam do Pibid-Biologia-UFRJ, os conteúdos nos três anos do Ensino Médio variam em função das mudanças recentes nas diretrizes curriculares para o referido nível de ensino. Entretanto, de forma geral, a organização curricular é constituída no trabalho de temas ligados à citologia e à ecologia no primeiro ano; à diversidade dos seres vivos no segundo ano e, por fim, aos conhecimentos mais complexos relacionados à genética, evolução e ecologia.

Dentro das diretrizes curriculares do MEC para os cursos de Graduação em Ciências Biológicas, incluindo as licenciaturas, os eixos principais de conteúdo conceitual a serem abordados no curso são:

1.Biologia celular, molecular e evolução, com visão ampla da organização e interações biológicas construída a partir do estudo da estrutura molecular e celular, função e mecanismos fisiológicos da regulação em modelos eucariontes, procariontes e de partículas virais, fundamentados pela informação bioquímica, biofísica, genética e imunológica; compreensão dos mecanismos de transmissão da informação genética, em nível molecular, celular e evolutivo;

2.Diversidade biológica, isto é, o conhecimento da classificação, filogenia, organização, biogeografia, etologia, fisiologia e estratégias adaptativas morfofuncionais dos seres vivos;

3.Ecologia, em que estão incluídos conteúdos envolvendo as relações entre os seres vivos e desses com o ambiente ao longo do tempo geológico; conhecimento da dinâmica das populações, comunidades e ecossistemas, da conservação e manejo da fauna e flora e da relação saúde, educação e ambiente;

4.Fundamentos das ciências exatas e da terra com conhecimentos matemáticos, físicos, químicos, estatísticos, geológicos e outros fundamentais para o entendimento dos processos e padrões biológicos;

5.Fundamentos filosóficos e sociais que deve experimentar discussões e reflexões sobre aspectos éticos e legais relacionados ao exercício profissional. Além disso, a estrutura curricular deve prever conhecimentos básicos de: História, Filosofia e Metodologia da Ciência, Sociologia e Antropologia, para dar suporte à sua atuação profissional na sociedade, com a consciência de seu papel na formação de cidadãos.

Ao compararmos os conteúdos da estrutura curricular do Curso de Licenciatura em Ciências Biológicas da UFRJ com aqueles desenvolvidos nas escolas onde o projeto Pibid-Biologia-UFRJ atua, percebemos algumas incongruências, como por exemplo, uma certa concentração no eixo "biodiversidade" na estrutura curricular do curso de Graduação da UFRJ. Os conteúdos ligados a este eixo, como a biodiversidade animal, vegetal e de outros reinos, não são normalmente desenvolvidos no Ensino Médio, na maioria das vezes por falta de tempo hábil. Os 
outros eixos apresentam boa representatividade nos conteúdos nas diversas práticas desenvolvidas e trabalhadas nas escolas, entretanto, os temas transversais ainda são pouco explorados. A Tabela 1 apresenta um panorama geral, por eixo, dos conteúdos que são trabalhados na Graduação e no Ensino Médio, acompanhados de seus respectivos temas transversais.

Tabela 1: Componentes curriculares do Curso de Ciências biológicas por eixo, conteúdos abordados no Ensino Médio e temas transversais desenvolvidos pelo projeto PibidBiologia-UFRJ.

\begin{tabular}{|c|c|c|c|}
\hline EIXOS & $\begin{array}{c}\text { GRADUAÇÃO } \\
\text { (Ciências Biológicas - UFRJ) }\end{array}$ & $\begin{array}{c}\text { ENSINO MÉDIO } \\
\text { (Escolas } \\
\text { Estaduais do Rio } \\
\text { de Janeiro } \\
\text { participantes do } \\
\text { Pibid-Biologia) }\end{array}$ & $\begin{array}{c}\text { TEMAS } \\
\text { TRANSVERSAIS/ } \\
\text { TECNOLOGIAS }\end{array}$ \\
\hline $\begin{array}{c}\text { Biologia } \\
\text { celular, } \\
\text { molecular e } \\
\text { evolução }\end{array}$ & $\begin{array}{c}\text { Biologia geral (citologia) } \\
\text { Embriologia Geral } \\
\text { Histologia } \\
\text { Genética Básica } \\
\text { Bioquímica Básica I e II } \\
\text { Evolução. } \\
\end{array}$ & $\begin{array}{l}\left.\text { Citologia ( } 1^{\circ} \text { ano }\right) \\
\left.\text { Genética ( } 3^{\circ} \text { ano }\right) \\
\text { Evolução }\left(3^{\circ} \text { ano }\right)\end{array}$ & $\begin{array}{l}\text { Saúde: câncer, } \\
\text { doenças } \\
\text { hereditárias }\end{array}$ \\
\hline $\begin{array}{l}\text { Diversidade } \\
\text { biológica: }\end{array}$ & $\begin{array}{c}\text { Introdução à Zoologia e Protistas } \\
\text { Heterotróficos } \\
\text { Diversidade Biológica de Porífera } \\
\text { Cnidária, Ctenophora e Portostomia I } \\
\text { Diversidade Biológica de Protostomia II } \\
\text { Diversidade Biológica de Deuterostomia } \\
\text { Biologia de Microrganismos } \\
\text { Botânica I, Botânica II Botânica III } \\
\text { (Anatomia) } \\
\text { Botânica IV (Fisiologia) }\end{array}$ & $\begin{array}{l}\text { Zoologia }\left(2^{\circ} \text { ano }\right) \\
\left.\text { Botânica ( } 2^{\circ} \text { ano }\right)\end{array}$ & $\begin{array}{c}\text { Biodiversidade } \\
\text { Bioprospecção } \\
\text { Plantas Medicinais }\end{array}$ \\
\hline Ecologia & $\begin{array}{c}\text { Elementos de Ecologia } \\
\text { Ecologia Básica } \\
\text { Biologia marinha Básica }\end{array}$ & $\begin{array}{l}\text { Ecologia }\left(1^{\circ} \text { e } 3^{\circ}\right. \\
\text { anos })\end{array}$ & $\begin{array}{l}\text { Educação } \\
\text { Ambiental }\end{array}$ \\
\hline $\begin{array}{l}\text { Fundamentos } \\
\text { das ciências } \\
\text { exatas e da } \\
\text { terra }\end{array}$ & $\begin{array}{c}\text { Complementos de Química I e II } \\
\text { Complementos de Matemática Física } \\
\text { para Ciências Biológicas Estatística e } \\
\text { Biofísica }\end{array}$ & $\begin{array}{c}\text { Matemática, } \\
\text { Química e Física }\end{array}$ & $\begin{array}{l}\text { Rodas de leitura: } \\
\text { Super-Heróis }\end{array}$ \\
\hline $\begin{array}{c}\text { Fundamentos } \\
\text { filosóficos e } \\
\text { sociais }\end{array}$ & Metodologia Científica & $\begin{array}{l}\text { Variável ( } 2 \text { das } 4 \\
\left.\text { escolas no } 1^{\circ} \text { ano }\right)\end{array}$ & $\begin{array}{l}\text { Investigação } \\
\text { científica }\end{array}$ \\
\hline
\end{tabular}


Neste sentido, as atividades propostas pelo projeto Pibid-Biologia suprem em parte essa lacuna e trazem para os alunos e professores supervisores, ideias e ações que auxiliam nos processos de ensino-aprendizagem. Entre os conteúdos trabalhados durante as atividades do Pibid-Biologia, percebemos que a "célula" ainda apresenta certa dificuldade de compreensão pelos estudantes do Ensino Médio. Neste conteúdo, os temas transversais despertaram nos alunos do Colégio César Pernetta o interesse por conhecer mais profundamente a estrutura celular e seu funcionamento, e mencionaram a sua curiosidade em ver células por meio da microscopia ótica. Motivados pelo interesse em conhecer melhor as estruturas celulares, aliado ao fato de que a instituição não possuía microscópios, os licenciandos Pibid-Biologia levaram dois instrumentos para atividades na escola. A atividade trouxe repercussões positivas consideráveis na escola. Os alunos concretizaram as suas concepções em cartazes e maquetes que ficaram expostas para toda a escola durante a Feira de Ciências do colégio. Percebemos que as dificuldades iniciais apresentadas pelos alunos sobre a estrutura celular e seu funcionamento foram, em grande parte, suprimidas, principalmente porque o tema explorado levou em consideração o interesse dos alunos, aliado ao fato de que tiveram a oportunidade de ver, na prática, a estrutura celular.

De acordo com Medina (1987), os conteúdos trabalhados em sala de aula necessitam de uma adequação à realidade social, cognitiva/motora, política e histórica do aluno. As propostas pedagógicas devem considerar o contexto sociocultural dos estudantes e de seus professores, com uma ênfase em processos de ensino-aprendizagem mais significativos e instigantes. Ressaltamos aqui que a maneira como o conteúdo é selecionado, organizado e trabalhado com os alunos facilitará ou dificultará a aprendizagem, razão pela qual é imprescindível o cuidado com as estratégias de ensino adotadas. Isso pressupõe que as relações em sala de aula e outros espaços escolares sejam calcadas dentro de uma perspectiva mais horizontal. Ainda que o professor ou no caso do Pibid-Biologia, os licenciandos e supervisores geralmente proponham a atividade, concordamos com uma postura dialógica e alteritária, que valoriza os processos de ensino-aprendizagens colaborativos entre alunos e professores. Neste sentido, o projeto Pibid-UFRJ se constitui como uma proposta relevante para a reflexão da prática pedagógica tanto na Educação Básica quanto na Educação Superior.

\section{A Pós-Graduação e o projeto Pibid-Biologia-UFRJ}

O Plano Nacional de Pós-Graduação (PNPG) 2005-2010 foi aprovado pelo Ministro da Educação, Tarso Genro, no dia 5 de janeiro de 2005. Dentro da proposta, a preocupação por uma maior integração da Pós-Graduação com a Graduação ficou sob a responsabilidade das instituições que ministram estes cursos. Neste mesmo documento os dados apresentados pelo PNPG demonstram que a necessidade de capacitação de docentes, tanto para a educação básica quanto para a superior, continua sendo uma das tarefas centrais da Pós-Graduação brasileira. O panorama apresentado ao longo desse documento indica que a expansão do sistema deve incluir a qualificação dos professores da educação básica. A necessidade de tal ação para os educadores do Ensino Fundamental, Médio e Técnico exige uma reflexão sobre qual seria o melhor caminho a ser seguido para atender a essa demanda. 
Neste sentido, além dos programas de Pós-Graduação envolvidos na pesquisa educacional, o estágio de docência tem se constituído numa possibilidade real da participação da Pós-Graduação em cursos de Graduação. O estágio de docência é uma atividade curricular para estudantes de Pós-Graduação stricto-sensu, sendo definida como a participação do aluno em atividades de ensino na instituição, sob a supervisão de seu orientador. É obrigatória para todos os alunos de Doutorado que recebem bolsa Capes por pelo menos 12 meses e optativa para os demais. Seu principal objetivo é aprimorar a formação do pós-graduando para atividade didática de Graduação. Em nossa experiência na UFRJ, os alunos estagiários docentes de disciplinas do curso de Graduação têm participado da preparação de algumas atividades desenvolvidas e aplicadas pelos próprios, por meio do Pibid, nas escolas vinculadas ao programa. A participação dos alunos de Pós-Graduação tem sido importante em diversos pontos, tais como: acesso e ou preparo de coleções biológicas de conteúdo mais particular (laminários, herbários, insetários entre outros); aprofundamento de conteúdos mais específicos nas áreas de interesse dos alunos de Pós-Graduação; bem como, a troca de experiências e informações geradas a partir das aulas práticas do componente curricular do curso com participação do estagiário de docência e as práticas desenvolvidas no contra turno das escolas vinculadas ao programa.

Durante a preparação de algumas atividades dialogadas contamos com a expertise de um mestrando e um doutorando do Programa de Pós-Graduação em Botânica (Museu Nacional/UFRJ) e do Programa de Pós-Graduação em Biodiversidade e Biologia Evolutiva (UFRJ). Eles organizaram o material biológico utilizado nas aulas práticas sobre diversidade biológica, orientaram e auxiliaram os alunos de graduação na identificação. Por exemplo, na aula temática e transversal sobre o "Mar", tivemos a coleta de vários materiais que necessitavam identificação como algas e invertebrados, bem como esclarecimentos sobre a biologia de alguns desses grupos biológicos menos familiares aos alunos. Tivemos a participação deles também em uma aula prática sobre célula vegetal, onde atuaram como monitores esclarecendo dúvidas sobre os tecidos encontrados em cortes anatômicos de caule e folhas do boldo, uma planta medicinal cultivada na escola.

Na nossa experiência no tema transversal desenvolvimento sustentável, incluído nas primeiras discussões dos conteúdos de ecologia, os alunos de PósGraduação auxiliaram os alunos integrantes do projeto Pibid em coletas botânicas em áreas de mata ciliar próxima ao Colégio Sargento Wolff. Os alunos Pibid participaram de atividades de identificação do material e análise dos resultados no laboratório de Diversidade e Evolução do Instituto de Biologia-UFRJ. Este trabalho foi apresentado, na escola, aos alunos participantes do projeto. A atividade gerou ao mesmo tempo reflexões sobre como esta pesquisa estaria ligada ao aluno, seu entorno e sua realidade, além de reforçar conteúdos abordados na sala de aula como a poluição e a conservação do meio ambiente.

Ao realizarmos as atividades do projeto Pibid-Biologia-UFRJ e discutirmos os resultados com os alunos e professores envolvidos, compreendemos o impacto positivo que tais práticas contextualizadoras têm na promoção de processos de ensino-aprendizagem mais significativos. Nesse sentido, concordamos com a proposta de trabalho apontada por Oliveira (2005, p. 248), que afirma: 
é necessário um planejamento do ensino, partindo do que os alunos já sabem, e em seguida inserir novos conceitos, fornecendo assim situações que possam ampliar suas concepções acerca de um determinado assunto, propiciando-lhes argumentos para que possam refletir sobre os fenômenos que o cercam.

Assim, defendemos uma relação mais próxima entre professores e alunos da Educação Básica bem como professores, alunos de Graduação e Pós-Graduação das IES, tornando a formação de todos mais integrada e abrangente. A aproximação entre alunos de Pós-Graduação com licenciandos e com alunos da Educação Básica pode ser uma excelente estratégia para diminuir a distância entre a Academia, a Educação Básica e a Sociedade. Essa aproximação oportuniza que as pesquisas desenvolvidas nas IES possam ser divulgadas e discutidas também em comunhão com outros segmentos educacionais.

\section{Considerações Finais}

Diante das reflexões tecidas neste artigo, tivemos a oportunidade de apresentar a importância de se estabelecer maiores vínculos multidirecionais entre a Pós-Graduação, a Graduação e o Ensino Médio. No contexto da estrutura curricular do Curso de Licenciatura em Ciências Biológicas da UFRJ, compreendemos que o Pibid constitui em uma proposta interessante para promover novos processos de ensino-aprendizagem com os alunos do Ensino Médio. Os documentos oficiais apresentados brevemente neste texto - LDB, PCN's e PNPG -, apontam perspectivas de trabalho que julgamos interessantes e necessárias para que os conhecimentos científicos sejam melhor explorados e amplamente divulgados nos diferentes níveis de ensino.

Longe de acreditar que os documentos oficiais sejam, por si só, capazes de levar melhorias à qualidade do ensino e da aprendizagem às instituições educacionais, concordamos que o fazer pedagógico exige reflexão permanente e o compromisso ético no trabalho em sala de aula. Desta forma, enfatizamos a necessidade de repensar determinadas práticas pedagógicas em que os professores sejam subordinados a receituários pedagógicos que desconsiderem os diferentes contextos socioculturais e que impossibilitem a autonomia docente nos processos de ensinar e aprender com os estudantes. A possibilidade de se estabelecer maiores vínculos entre os diferentes níveis de ensino permite que os conhecimentos das ciências biológicas sejam amplamente discutidos entre professores e estudantes, que passam a buscar caminhos e alternativas pedagógicas no trabalho com o mundo dos seres vivos na sala de aula. O projeto Pibid-UFRJ é uma oportunidade rica e única para se conhecer os cotidianos das escolas públicas do Rio de Janeiro, e os caminhos trilhados no desenvolvimento do trabalho com os conhecimentos das ciências biológicas certamente vêm contribuindo com o espaço escolar e com a própria formação dos estudantes da UFRJ. 


\title{
The Institutional Scholarship Program PIBID as a proposal for the reflection of Biological Sciences in Primary, Undergraduate and Graduate Education
}

\begin{abstract}
The aim of this paper is to discuss the content addressed in the first year of high school and transversal subjects in the context of the curricular structure of the Biology degree course in the Federal University of Rio de Janeiro (UFRJ) and how the Pibid constitutes a powerful tool for stimulating reflections about this structure. Also aims to present the contribution of the graduate students in this process through their performance in the internship teaching in the components of the course.
\end{abstract}

KEYWORDS: High School. Pibid. Biology Course, teaching. 


\section{NOTAS}

10 coordenador institucional responde por todas as áreas de atuação do Pibid dentro da Instituição de Ensino Superior (IES). Para cada área existe um coordenador, que no nosso caso, é um docente do Instituto de Biologia. Os professores supervisores, por sua vez, são os professores das respectivas disciplinas nas escolas estaduais, e cada escola possui apenas um professor supervisor.

20 nosso objetivo aqui não é promover uma análise detalhada sobre os aspectos da leitura e da escrita em contextos escolares. Para outras reflexões sobre o tema, ver os trabalhos de Goulart $(2006)$, Soares $(2002,1998)$ e Nunes e Kramer (2011).

3 Para maiores informações sobre as atividades realizadas pelo projeto PibidUFRJ nas escolas do Ensino Médio, acesse o site http://www.pibid.pr1.ufrj.br/

\section{REFERÊNCIAS}

ALVES, Nilda. Decifrando o pergaminho - os cotidianos das escolas nas lógicas das redes cotidianas. In: OLIVEIRA, Inês Barbosa; ALVES, Nilda (Orgs.). Pesquisa nos/dos/com os cotidianos das escolas - sobre redes de saberes. 3. Ed. Petrópolis: DP et Alii, 2008, p. 16-38.

BRANDÃO, Carlos Rodrigues. A pergunta a várias mãos: a experiência da partilha através da pesquisa na educação. São Paulo: Cortez, 2003.

BRASIL. Secretaria de Educação Fundamental. Parâmetros Curriculares Nacionais: ciências naturais. Brasília: MEC/SEF, 1998.

BRASIL. Lei de Diretrizes e Bases da Educação Nacional: Lei no 9.394, de 20.12.1996 (Lei Darcy Ribeiro) - Plano Nacional de Educação: Lei no 10.172, de 10 de janeiro de 2001 e legislação correlata e complementar. 2 Ed. Bauru: EDIPRO, 2001.

CARVALHO, Maria Cristina. Infância, leitura e escrita - entrando numa escola de formação de professores. In: FAZOLO, Eliane; CARVALHO, Maria Cristina; LEITE, Maria Isabel; KRAMER, Sonia. (Orgs.). Educação Infantil em curso. Rio de Janeiro: Ravil, 1997, p. 96-124. 
FARIA JÚNIOR, A. \&, FARIA, E. J. C. Didática de Educação Física. In: FARIA JÚNIOR, A. (Org.) Uma introdução à educação física. Niterói - RJ: Corpus, 1999.

FERRARI, Anderson; CASTRO, Roney Polato. "Nossa! Eu nunca tinha parado para pensar nisso!" - gênero, sexualidades e formação docente. Interfaces da Educação, Paranaíba, v. 3, n. 7, p. 68-83, 2013.

FREIRE, Paulo. Pedagogia do Oprimido. Rio de Janeiro: Paz e Terra, 1987.

GOULART, Cecília. Letramento e modos de ser letrado: discutindo a base teóricometodológica de um estudo. Revista Brasileira de Educação, v .11, n. 33, set/dez 2006, p. 450-460.

JACOBUCCI, Daniela Franco Carvalho. Divulgação científica a conta-gotas na formação do biólogo. In: FONTOURA, Helena Amaral; SILVA, Marco (Orgs.). Práticas pedagógicas, linguagem e mídias: desafios à Pós-graduação em educação em suas múltiplas dimensões. Rio de Janeiro: ANPEd Nacional, 2011, p. 178-192.

KRAMER, Sonia. Por entre as pedras: arma e sonho na escola. 3. Ed. São Paulo: Ática, 2007.

LEITE, Maria Isabel. O que falam de escola e saber as crianças da área rural? Um desafio da pesquisa no campo. In: KRAMER, Sonia; LEITE, Maria Isabel (Orgs.). Infância: fios e desafios da pesquisa. 9. Ed. São Paulo: Papirus, 2007, p. 73-96.

MARINHO, Simão Pedro P. Novas tecnologias e velhos currículos; já é hora de sincronizar. Revista E-curriculum, São Paulo, v. 02, n. 03, p. 01-28, dez. 2006.

MEDINA, João Paulo Subirá. A Educação Física cuida do corpo e mente. Campinas: Papirus, 1987.

MOREIRA, Antonio Flavio Barbosa; KRAMER, Sonia. Contemporaneidade, educação e tecnologia. Educação \& Sociedade, Campinas, v. 28, n. 100, p. $1037-$ 1057, out. 2007.

NÓVOA, António. Os professores na virada do milênio: do excesso dos discursos à pobreza das práticas. Educação e Pesquisa, São Paulo, v. 25, n. 1, p. 11-20, jun. 1999. com Paulo Freire e Mikhail Bakhtin. Revista Contemporânea de Educação, v. 6, n. 11, p. 26-47, jan./jul. 2011. 
OLIVEIRA, Silmara Sartoreto. Concepções alternativas e ensino de biologia: como utilizar estratégias diferenciadas na formação inicial de licenciados. Educar em Revista, Curitiba, n. 26, p. 233-250, 2005.

OSWALD, Maria Luiza; ROCHA, Sérgio Luiz. Sobre juventude e leitura na "idade mídia": implicações para políticas e práticas curriculares. Educar em Revista, Curitiba, n. 47, p. 267-283, jan./mar. 2013.

SAVIANI, Nereide. Saber escolar, currículo e didática: problemas da unidade conteúdo/método no processo pedagógico. Campinas : Autores Associados, 1994.

SOARES, Magda. Novas práticas de leitura e escrita: letramento na cibercultura. Educação e Sociedade, Campinas, v. 23, n. 81, p. 143-160, dez. 2002.

SOARES, Magda. Letramento: um tema em três gêneros. Belo Horizonte, Autêntica, 1998.

Recebido: 04 fev. 2015

Aprovado: 06 out. 2016

DOI: http://dx.doi.org/10.3895/rbect.v9n2.1973

Como citar: SAKURAGUI, C. M.; NUNES, A. P. S. F.; JUNIOR, D. R. C. O Programa Institucional de Bolsas de Iniciação à Docência como proposta para a reflexão das Ciências Biológicas na Educação Básica, Graduação e Pós-Graduação. Revista Brasileira de Ensino de Ciência e Tecnologia v. 9, n. 2, 2016. Disponível em: <https://periodicos.utfpr.edu.br/rbect/article/view/1973>. Acesso em: 8/11/2016.

\section{Correspondência:}

Av Monteiro Lobato, 205, 84010-060 - Ponta Grossa - Paraná

Direito autoral: Este artigo está licenciado sob os termos da Licença Creative Commons-Atribuição 4.0 Internacional. 